\title{
Factors in the success of the subcutaneous central venous port catheter in 626 colorectal carcinoma patients: long-term follow-up results according to the treatment groups
}

\author{
BK Aribas ${ }^{*}$, T Uylar, MY Aksoy, I Turker, F Yildiz, R Tiken, I Akdulum \\ From International Cancer Imaging Society Meeting and 15th Annual Teaching Course (ICIS 2015) \\ London, UK. 5-7 October 2015
}

\begin{abstract}
Aim
Our purpose is retrospectively to investigate the effect of factors on the patency of subcutaneous central venous port catheters inserted to 626 colorectal carcinoma patients.

\section{Patients and methods}

Subcutaneous central venous port catheters were inserted to 1,408 patients. 241 were female, 383 were male. Patients were given chemotherapy agents as bevacizumab in 106, cetuximab in 30 , and outside of these target-directed agents in 488 . The groups to chemotherapy time were divided by 3 days cut-off. Age, gender, jugular-subclavian access, the chemotherapy to be given in 3 days as bevacizumab, cetuximab, other chemotherapy agents were also investigated.
\end{abstract}

\section{Results}

The average age was $57.7 \pm 11.3$. The average follow-up period was $445.2 \pm 387.8$ days (1-1787 days). The catheters were removed depending on the port complications in 6 patients of bevacizumab group, 3 patients of cetuximab, and 11 patients of other chemotherapy group. A significant difference was observed in 3 days chemotherapy between cetuximab and out-of bevacizumab-cetuximab groups ( $\mathrm{p}=0.013$ ), also between bevacizumab and out-of bevacizumab-cetuximab the groups $(\mathrm{p}=0.007)$. No significant difference was observed out of 3 days chemotherapy ( $p>0.05)$. There was no difference between groups in Cox regression test. Significant difference was observed in

* Correspondence: bilginaribas@hotmail.com

Dr. Abdurrahman Yurtaslan Ankara Oncology Education and Research Hospital Ankara, Turkey creativecommons.org/licenses/by/4.0), which permits unrestricted use, distribution, and reproduction in any medium, provided the original work is properly cited. The Creative Commons Public Domain Dedication waiver (http://creativecommons.org/publicdomain/ zero/1.0/) applies to the data made available in this article, unless otherwise stated. 